\title{
Desenvolvimento de queijo minas frescal adicionado de Lactobacillus acidophilus produzido a partir de retentados de ultrafiltração
}

\author{
Development of Brazilian Minas soft cheese with Lactobacillus acidophilus \\ produced with retentates obtained by ultrafiltration of milk
}

\author{
Eliana Paula RIBEIRO ${ }^{1 *}$, Luciana Guedes SIMÕES ${ }^{1}$, Cynthia Hyppolito JURKIEWICZ1
}

\begin{abstract}
Resumo
Este trabalho teve por objetivos: desenvolver um queijo probiótico tipo minas frescal a partir de retentados de ultrafiltração, estudar a sobrevivência da bactéria probiótica Lactobacillus acidophilus durante a vida de prateleira do produto e avaliar as alterações físico-químicas e sensoriais do produto. O queijo foi produzido a partir de retentados, obtidos a partir da ultrafiltração de leite integral até o fator de concentração volumétrico de 5:1. Os retentados pasteurizados foram inoculados com L. acidophilus, de forma a obter uma população inicial no queijo de $10^{6}, 10^{7}$ e $10^{8}$ UFC. $^{-1}$. Foram realizadas análises microbiológicas, para contagem das bactérias probióticas em intervalos de 7 dias durante sua estocagem, análises físico-químicas e análise sensorial, para verificar a existência de preferência. Foi utilizado o delineamento de blocos completos com uma variável em três níveis e três repetições. Os resultados obtidos mostraram que a concentração de inóculo não influenciou de forma significativa ( $\mathrm{p}>0,05)$ os valores de $\mathrm{pH}$, índices de extensão e de profundidade de proteólise. Ao longo dos 28 dias de estocagem, o decréscimo da população de $L$. acidophilus não foi significativo $(\mathrm{p}>0,05)$ para os três queijos avaliados. A análise sensorial mostrou a existência de diferença e preferência não significativas $(\mathrm{p}>0,05)$ entre os queijos com diferentes populações de L. acidophilus. Concluiu-se que o queijo minas frescal produzido a partir de retentados de ultrafiltração apresenta grande potencial como alimento probiótico.

Palavras-chave: queijo minas frescal probiótico; ultrafiltração em queijos.
\end{abstract}

\begin{abstract}
Probiotic Brazilian Minas soft cheese was produced by ultrafiltration. Cheese was produced from retentates obtained from ultrafiltration of milk with a volumetric concentration factor of 5:1. The pasteurized retentates were inoculated with 106, 107, and $108 \mathrm{cfu}^{\mathrm{mL}} \mathrm{m}^{-1}$ of Lactobacillus acidophilus. The viability of $L$. acidophilus, protein breakdown, and $\mathrm{pH}$ changes were monitored during cheese storage at $5{ }^{\circ} \mathrm{C}$ for $1,7,14,21$, and 28 days. The chemical composition and the sensory acceptability of the cheese were also determined. The experimental design consisted of complete blocks with one variable, three levels, and three replications. The results show that different populations of $L$. acidophilus did not significantly change cheese composition, $\mathrm{pH}$, and proteolysis $(\mathrm{p}>0.05)$. The population of L. acidophilus during the 28 days of storage period was not significantly affected $(\mathrm{p}>0.05)$. The sensorial analysis showed a non-significant preference among the three types of cheese. It can be said that the probiotic Brazilian Minas soft cheese produced from retentates has a great potential as a probiotic food.

Keywords: probiotic; UF probiotic cheese.
\end{abstract}

\section{Introdução}

Os alimentos probióticos fazem parte do grupo dos alimentos funcionais, pois, além de suas qualidades nutricionais, afetam beneficamente uma ou mais funções relevantes do organismo do consumidor.

Dentre os benefícios à saúde produzidos por bactérias probióticas, podem-se citar: redução da intolerância à lactose; inibição de microrganismos patogênicos; prevenção de diarréia; redução dos níveis de colesterol; aumento da resposta imunológica; e prevenção de câncer de cólon (SAARELA et al., 2002; SANDERS, 2003; SCHMID et al., 2006).

Os microrganismos utilizados como probióticos são, predominantemente, diferentes espécies e linhagens dos gêneros Lactobacillus e Bifidobacterium. A principal razão para esta escolha é o fato destes dois gêneros serem habitantes predominantes do intestino humano, sendo: Lactobacillus do intestino delgado e Bifidobacterium do intestino grosso. L. acidophilus é o microrganismo probiótico mais utilizado e estudado nos últimos anos (O’SULLIVAN, 2006).

No mercado nacional, os alimentos probióticos estão restritos a diversos tipos de leites fermentados, enquanto na Europa, Estados Unidos e Canadá, estão também disponíveis diversos tipos de queijos e cereais. Para o desenvolvimento de um alimento contendo bactérias probióticas, devem ser considerados vários fatores, tais como, atividade de água, temperatura de processamento e armazenamento, tempo de estocagem, conteúdo de oxigênio, $\mathrm{pH}$, teor de sal e os outros ingredientes

Recebido para publicação em 24/4/2007

Aceito para publicação em 6/1/2009 (002485)

Instituto Mauá de Tecnologia, Engenharia Química e de Alimentos, Centro Universitário, Praça Mauá 01, CEP 09580-900, São Caetano do Sul - SP, Brasil,

E-mail: elianaribeiro@maua.br; cynthia@maua.br

${ }^{*}$ A quem a correspondência deve ser enviada 
presentes, de forma que a cultura probiótica permaneça viável e em número elevado durante a vida de prateleira do produto. Para que os benefícios à saúde produzidos por bactérias probióticas sejam obtidos, é necessária a ingestão de uma dose diária de $10^{8}$ a $10^{10} \mathrm{UFC}$, o que representa o consumo de $100 \mathrm{~g}$ do alimento, contendo, no mínimo, $10^{6} \mathrm{UFC}^{-1}{ }^{-1}$ (REID et al., 2003).

Dentre os alimentos avaliados para a incorporação de bactérias probióticas, estudos mostram que vários tipos de queijos apresentam grande potencial (BURITI et al., 2005b; CORBO et al., 2001; CUNHA et al., 2002b; DAIGLE et al., 1999; GARDINER et al., 1999; JURKIEWICZ, 1999; GOMES et al., 1998; STANTON et al., 1998; VINDEROLA et al., 2001). Os queijos, em geral, apresentam algumas vantagens em relação a outros produtos probióticos. A maioria possui $\mathrm{pH}$ mais elevado que iogurtes $\mathrm{e}$ leites fermentados, o que torna o meio mais estável para a sobrevivência das culturas probióticas por um período mais longo. Além disso, os queijos, por apresentarem uma quantidade de gordura relativamente alta, oferecem uma proteção para a bactéria probiótica durante sua passagem pelo trato gastrintestinal (GARDINER et al., 1999). Por outro lado, alguns queijos apresentam um período de maturação muito longo, o que dificulta a sobrevivência do microrganismo probiótico.

O queijo Minas frescal é um dos queijos mais populares e o mais produzido no Brasil (75\% do total de queijos), apresenta alto teor de umidade, massa branca, consistência mole, textura fechada com algumas olhaduras irregulares, sabor suave a levemente ácido. É obtido por meio de coagulação enzimática do leite com ácido lático ou fermento. Sua produção é disseminada e, por isso, tem considerável variação no padrão. É um queijo fresco, sem nenhuma maturação e apresenta um tempo de vida útil pequeno (até 20 dias). Tais características tornam o queijo Minas Frescal um alimento próprio para a incorporação de microrganismos probióticos.

A produção do queijo Minas frescal, utilizando retentados obtidos a partir da ultrafiltração de leite, resulta em maior rendimento e confere à massa uma textura mais sólida e fechada e maior tempo de vida útil, além de um padrão uniforme de sabor.

A elevação do teor de proteínas e dos sais minerais nos retentados provoca o aumento de seu poder tamponante, influenciando no desenvolvimento de fermentos lácticos e sua consequente acidificação (BRULE et al., 1974; MISTRY; KOSIKOWSKI, 1985).

Este trabalho teve por objetivos: desenvolver um queijo tipo minas frescal probiótico a partir de retentados de ultrafiltração; avaliar suas características físico-químicas e sensoriais; e estudar a sobrevivência da bactéria probiótica L. acidophilus La 145 durante a vida de prateleira do produto.

\section{Material e métodos}

\subsection{Processo de ultrafiltração de leite}

Leite integral pasteurizado e resfriado foi aquecido a $55^{\circ} \mathrm{C}$ em um pasteurizador Tetra Hoyer, modelo Mix Complet 100, com capacidade para $100 \mathrm{~L}$, dotado de agitador e sistemas de aquecimento e resfriamento. A seguir, o leite foi transferido para o tanque de alimentação da unidade de ultrafiltração Tetra Alcross MF 1, contendo uma membrana mineral tubular de óxido de zircônio com suporte de carbono grafite, com área de $0,2 \mathrm{~m}^{2}$ e tamanho de poros de $0,1 \mu \mathrm{m}$, previamente limpa e sanificada. O leite foi concentrado até o fator de concentração volumétrico de 5:1, determinado a partir da redução de volume obtida durante o processo e controlado por medidas de vazão de permeado durante o mesmo processo. A temperatura foi mantida em $55^{\circ} \mathrm{C}$ através do controle da água de resfriamento da bomba de alimentação. A pressão transmembrana, determinada pela diferença entre pressão de entrada $(343 \mathrm{kPa})$ e saída $(264,8 \mathrm{kPa})$ de retentado, foi mantida em $79,2 \mathrm{kPa}$ durante o processamento.

Após a obtenção da concentração desejada, o processo foi interrompido, o retentado foi retirado do sistema e tratado térmicamente a $68^{\circ} \mathrm{C}$ por 10 minutos, seguido de resfriamento até $32{ }^{\circ} \mathrm{C}$ para a produção dos queijos. Imediatamente após a retirada do leite, foi realizada a limpeza do sistema de ultrafiltração.

\subsection{Fabricação do queijo a partir do retentado}

Para a produção do queijo minas frescal probiótico, foi utilizada a cultura comercial liofilizada de Lactobacillus acidophilus 145 (Danisco), mantida a $-18^{\circ} \mathrm{C}$ até o momento de sua utilização.

$\mathrm{O}$ retentado mantido a $32{ }^{\circ} \mathrm{C}$ no tanque para fabricação de queijo foi subdividido em três partes iguais (A, B e C). Cada parte foi inoculada com $L$. acidophilus de forma a obter as seguintes populações: $10^{6}, 10^{7}$ e $10^{8}$ UFC.mL ${ }^{-1}$, correspondendo respectivamente aos queijos A, B e C. A seguir, a cada parte foi adicionado $1,5 \%$ de sal e $0,07 \%$ de coagulante renina (Ch. Hansen) e a mistura foi homogeneizada por 1 minuto e acondicionada em embalagens de polietileno com capacidade para $0,50 \mathrm{~kg}$. Após a coagulação da massa nos potes, os queijos foram armazenados sob refrigeração a $5{ }^{\circ} \mathrm{C}$ durante 28 dias. Cada processamento foi realizado em triplicata.

\subsection{Análises sensorial, físico-químicas e microbiológicas}

Foram realizadas as seguintes determinações nos queijos após 1 dia de fabricação: pH (SILVA et al., 1997); acidez titulável (SILVA et al., 1997); nitrogênio total (WILLIAMS, 1984) com fator de conversão de 6,38; gordura (SILVA et al., 1997); cinzas (SILVA et al., 1997); sal (SILVA et al., 1997); umidade (WILLIAMS, 1984); e cálcio total (KINDSTED; KOSIKOWSKI, 1985). Em intervalos de 7 dias, foram realizadas as seguintes análises físico-químicas: pH (SILVA et al., 1997); acidez titulável (SILVA et al., 1997); nitrogênio total (WILLIAMS, 1984); e frações nitrogenadas (GRIPON et al., 1975). A partir das frações nitrogenadas determinadas durante o armazenamento, foram calculados os índice de extensão e profundidade de proteólise (WOLFSCHOON-POMBO, 1983).

A enumeração de L. acidophilus nos queijos também foi realizada em intervalos de 7 dias. Uma amostra de $10 \mathrm{~g} \mathrm{de}$ cada queijo foi homogeneizada com $90 \mathrm{~mL}$ de água peptonada $0,1 \%$ estéril, em um homogeneizador de amostra (Stomacher, 
Seward) e, em seguida, diluições decimais seriadas foram realizadas utilizando-se o mesmo diluente. Alíquotas de $0,1 \mathrm{~mL}$ de diluições adequadas foram adicionadas à superfície do ágar MRS (OXOID) e as placas incubadas em jarra com gerador de anaerobiose (Anaerogen, OXOID) a $43^{\circ} \mathrm{C}$ por 72 horas (JURKIEWICZ, 1999). Colônias características de L. acidophilus (diâmetro de 2 a $3 \mathrm{~mm}$ e borda irregular) foram enumeradas e confirmadas através de observação microscópica de morfologia.

Foi realizado teste de aceitabilidade nos queijos após 1 dia de fabricação, utilizando-se escala hedônica de 9 pontos, com 76 provadores não treinados, conforme descrito por Dutcosky, 1996.

\subsection{Planejamento experimental e análise estatística}

Os ensaios foram realizados segundo um delineamento de blocos completo, sendo a variável independente, população inicial de L. acidophilus nos queijos, estudada em três níveis $\left(10^{6}\right.$, $\left.10^{7} \mathrm{e} 10^{8} \mathrm{UFC} \cdot \mathrm{g}^{-1}\right)$. Cada tratamento foi realizado em triplicata, totalizando 9 ensaios.

Os resultados foram avaliados por Análise de Variância (ANOVA) realizada com o auxílio do programa estatístico MINITAB versão 15 e a comparação das médias foi realizada pelo teste de Duncan (DRUMOND et al., 1996). O nível de significância de $5 \%$ foi adotado para todos os testes.

\section{Resultados e discussão}

Na Tabela 1, é apresentada a composição físico-química dos queijos. Os resultados obtidos mostraram que não houve diferença significativa $(p>0,05)$ nos teores de umidade, gordura, cinzas, proteína, cálcio, sal e $\mathrm{pH}$ entre os queijos. Este resultado era esperado, uma vez que o processo foi o mesmo para todos os queijos e a única fonte de variação entre eles foi a população de bactéria probiótica. A bactéria L. acidophilus não possui atividade significativa sobre os principais componentes dos queijos e, portanto, sua concentração não poderia afetar a composição deles.

Os queijos apresentaram um teor mais elevado de umidade que os valores normalmente obtidos no queijo Minas frescal produzido pelo processo tradicional (DORNELLAS, 1997; VAN DENDER, 1995), o que pode ser atribuído à presença das

Tabela 1. Composição físico-química dos queijos após 1 dia de fabricação.

\begin{tabular}{lccc}
\hline Determinação & Queijo A & Queijo B & Queijo C \\
\hline Umidade (\%) & $67,7 \pm 0,9^{\mathrm{a}}$ & $68 \pm 2^{\mathrm{a}}$ & $68,4 \pm 0,6^{\mathrm{a}}$ \\
Gordura (\%) & $13,5 \pm 0,5^{\mathrm{a}}$ & $13,0 \pm 0,0^{\mathrm{a}}$ & $13,0 \pm 0,0^{\mathrm{a}}$ \\
Cinzas (\%) & $2,3 \pm 0,2^{\mathrm{a}}$ & $2,5 \pm 0,1^{\mathrm{a}}$ & $2,3 \pm 0,1^{\mathrm{a}}$ \\
Proteínas (\%) & $13,68 \pm 0,02^{\mathrm{a}}$ & $13,91 \pm 0,06^{\mathrm{a}}$ & $13,47 \pm 0,09^{\mathrm{a}}$ \\
Cálcio (\%) & $0,35 \pm 0,05^{\mathrm{a}}$ & $0,34 \pm 0,9^{\mathrm{a}}$ & $0,38 \pm 0,02^{\mathrm{a}}$ \\
Sal (\%) & $0,96 \pm 0,06^{\mathrm{a}}$ & $1,03 \pm 0,02^{\mathrm{a}}$ & $0,98 \pm 0,01^{\mathrm{a}}$ \\
pH & $6,56 \pm 0,01^{\mathrm{a}}$ & $6,51 \pm 0,05^{\mathrm{a}}$ & $6,53 \pm 0,04^{\mathrm{a}}$ \\
\hline
\end{tabular}

Onde: letras iguais na mesma linha indicam que não existe diferença significativa ao nível de $5 \%$ de significância $(\mathrm{p}>0,05)$. Valores médios resultantes de triplicatas, com os respectivos desvio padrão. proteínas do soro retidas devido ao processo de ultrafiltração, as quais aumentam a retenção de água no produto. Cunha et al. (2002a; b) também obtiveram valores mais elevados de teor de umidade nos queijos produzidos por ultrafiltração.

As variações de $\mathrm{pH}$ e dos índices de extensão e profundidade de proteólise, determinadas nos queijos durante 28 dias de armazenamento a $5{ }^{\circ} \mathrm{C}$, são apresentadas nas Figuras 1,2 e 3 . Os resultados obtidos mostraram a existência de diferença não significativa $(\mathrm{p}>0,05)$ entre os valores de $\mathrm{pH}$, índice de extensão e índice de profundidade de proteólise para os três tipos de queijos, os quais apresentaram os mesmos perfis de $\mathrm{pH}$ e dos índices de proteólise ao longo do tempo de estocagem, mostrando que a quantidade de inóculo adicionada não influenciou de

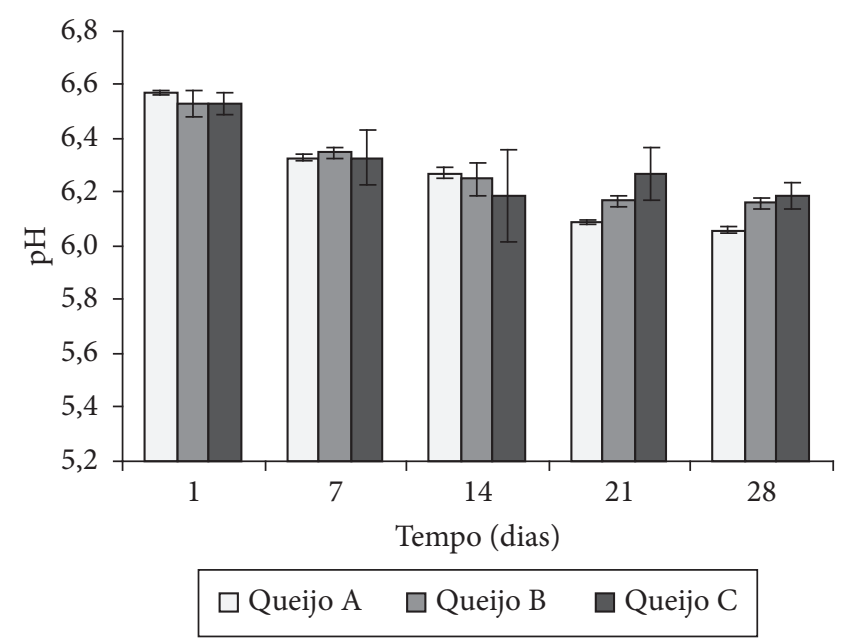

Figura 1. Variação de $\mathrm{pH}$ nos queijos A $\left(10^{6} \mathrm{UFC}^{-g^{-1}}\right)$; B $\left(10^{7} \mathrm{UFC} . \mathrm{g}^{-1}\right)$; e C $\left(10^{8} \mathrm{UFC}^{-1}\right)$ durante 28 dias de estocagem a $5{ }^{\circ} \mathrm{C}$.

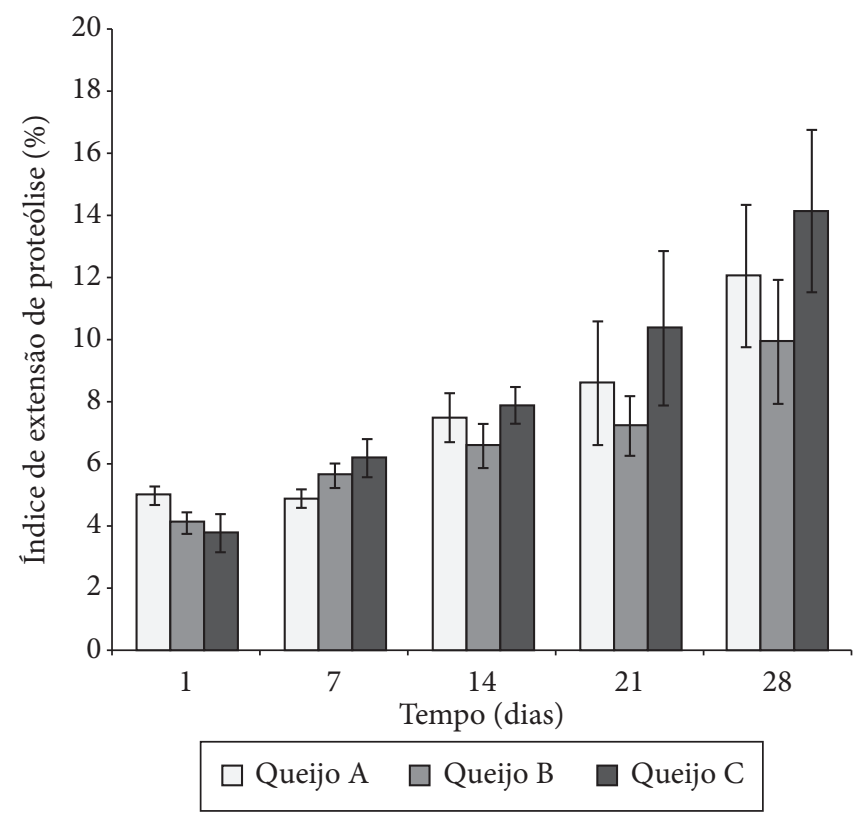

Figura 2. Variação do índice de extensão de proteólise (\%) nos queijos A (10 ${ }^{6}$ UFC. $\left.^{-1}\right)$; B (10 UFC. $\left.^{-1}\right)$; e C $\left(10^{8}\right.$ UFC. $\left.^{-1}\right)$ durante 28 dias de estocagem a $5^{\circ} \mathrm{C}$. 
forma significativa o $\mathrm{pH}$ e a proteólise do queijo. Entretanto, ao longo da estocagem, houve uma redução significativa do $\mathrm{pH}$ $(\mathrm{p}<0,05)$ e um aumento significativo dos índices de proteólise $(\mathrm{p}<0,05)$ de forma semelhante para os três tipos de queijos. Estes resultados concordam com os obtidos por Cunha et al. (2002b), que obtiveram uma redução de $\mathrm{pH}$ e aumento dos índices de proteólise ao longo do tempo de estocagem em queijo minas frescal produzido a partir de retentados sem adição de bactérias lácticas e atribuíram este comportamento ao maior teor de água que favoreceu o desenvolvimento da microbiota contaminante do leite.

A população média de L. acidophilus nos queijos A, B e C ao longo de 28 dias de armazenamento está apresentada na Tabela 2.

Durante os 28 dias de armazenamento, foi verificada uma redução não significativa $(\mathrm{p}>0,05)$ na população de L. acidophilus, para os queijos $\mathrm{A}, \mathrm{B}$ e $\mathrm{C}$, indicando que o queijo Minas Frescal produzido com retentado de leite é um meio adequado para a sobrevivência da bactéria probiótica. No queijo A, a população de $L$. acidophilus permaneceu ligeiramente abaixo de $10^{6} \mathrm{UFC}^{-1} \mathrm{~g}^{-1}$, o que poderia comprometer as propriedades funcionais deste produto (O'SULLIVAN, 2006). Por outro lado, nos queijos B e C, a população de L. acidophilus permaneceu

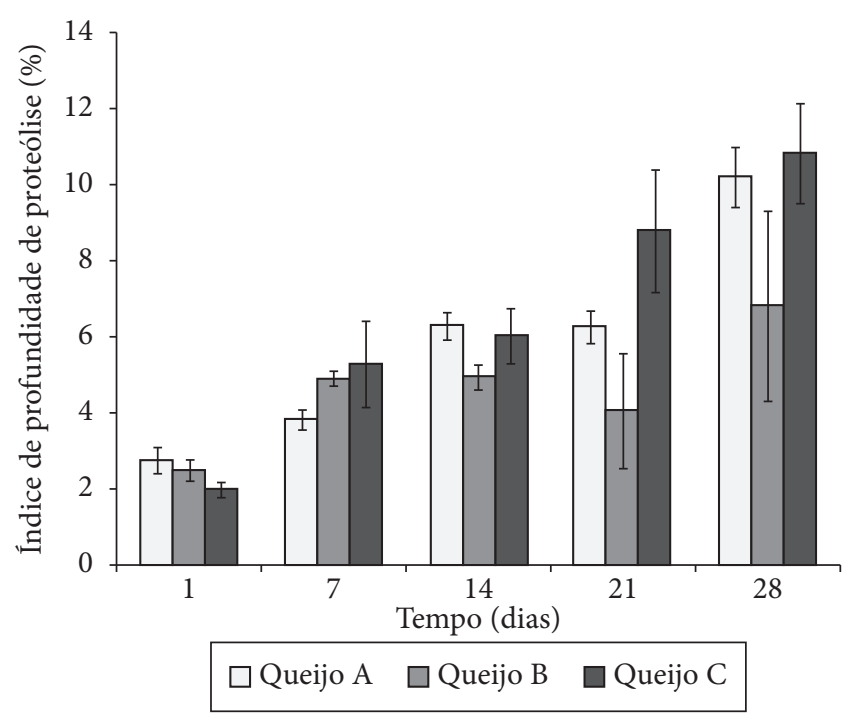

Figura 3. Variação do índice de profundidade da proteólise (\%) nos queijos A $\left(10^{6} \mathrm{UFC}_{\mathrm{g}} \mathrm{g}^{-1}\right)$; B $\left(10^{7} \mathrm{UFC}^{-g^{-1}}\right)$; e C $\left(10^{8} \mathrm{UFC}^{-g^{-1}}\right)$ durante 28 dias de estocagem a $5{ }^{\circ} \mathrm{C}$.

Tabela 2. População média de Lactobacillus acidophilus, nos queijos A,

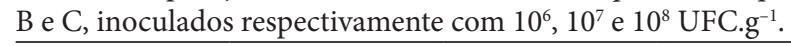

\begin{tabular}{cccc}
\hline \multirow{2}{*}{ Tempo (dias) } & \multicolumn{3}{c}{ L. acidophilus $\left(\right.$ Log UFC.g (1) $^{\star}$} \\
\cline { 2 - 4 } & Queijo A & Queijo B & Queijo C \\
\hline 0 & $5,9 \pm 0,2$ & $7,1 \pm 0,4$ & $7,9 \pm 0,1$ \\
7 & $5,7 \pm 0,3$ & $6,9 \pm 0,2$ & $7,8 \pm 0,1$ \\
14 & $5,9 \pm 0,1$ & $6,7 \pm 0,2$ & $7,5 \pm 0,5$ \\
21 & $5,5 \pm 0,7$ & $6,5 \pm 0,8$ & $7,4 \pm 0,6$ \\
28 & $5,4 \pm 0,6$ & $6,3 \pm 0,6$ & $7,4 \pm 0,6$ \\
\hline
\end{tabular}

${ }^{\star}$ Cada valor representa a média de três ensaios com o respectivo desvio padrão. sempre acima de $10^{6} \mathrm{UFC} \mathrm{g}^{-1}$, indicando que a população inicial no queijo deve ser, no mínimo, $10^{7} \mathrm{UFC}^{-\mathrm{g}^{-1}}$, de forma a garantir um número elevado do microrganismo probiótico durante a vida de prateleira do produto.

Buriti et al. (2005b), avaliaram a sobrevivência de L. acidophilus em queijo Minas frescal produzido com acidificação direta com ácido lático e também com adição de cultura mesófila (Lactococcus lactis subsp. lactis e L. lactis subsp. cremoris). Nos dois tipos de queijo, a cultura probiótica permaneceu viável durante 21 dias de armazenamento, no entanto, no queijo contendo a cultura mesófila, as contagens de L. acidophilus foram ligeiramente superiores, sugerindo um sinergismo entre os microrganismos. No queijo contendo apenas L. acidophilus, a concentração atingiu valores abaixo de $10^{6} \mathrm{UFC} . \mathrm{g}^{-1}$, assim como o observado para o queijo A no presente trabalho.

A sobrevivência de culturas probióticas em queijo fresco argentino produzido com retentado obtido por ultrafiltração foi avaliada por Vinderola et al. (2000). Os queijos foram produzidos utilizando-se diferentes combinações de $S$. thermophilus e Lactococcus lactis com culturas probióticas de Bifidobacterium, L. acidophilus e L. casei. Embora os produtos apresentassem teor de umidade de $58 \%$ e $\mathrm{pH}$ de 5,29 , valores inferiores aos dos queijos produzidos no presente trabalho $(68 \%$ e pH 6,5$)$, a redução da população L. acidophilus e Bifidobacterium foi menor que 1 ciclo logarítmico, enquanto a população de $L$. casei permaneceu constante durante 60 dias de armazenamento sob refrigeração.

A análise sensorial foi realizada com 76 provadores não treinados, os resultados obtidos são apresentados na Figura 4. A análise estatística dos resultados mostrou a existência de preferência não significativa $(\mathrm{p}=0,631)$ entre os três queijos.

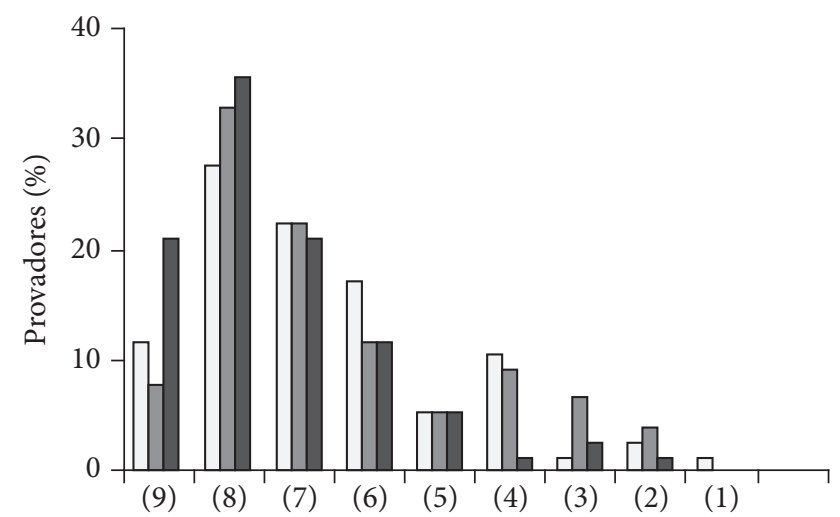

Gostei extremamente (9) Nem gostei, nem desgostei (5) Gostei muito (8) Desgostei ligeiramente (4) Gostei regularmente (7) Desgostei regularmente (3) Gostei ligeiramente (6) Desgostei muito (2) Desgostei extremamente (1)

$\square$ Queijo A $\square$ Queijo B $\square$ Queijo C

Figura 4. Resultados obtidos na análise sensorial nos queijos A, B e C, contendo L. acidophilus nas concentrações $10^{6}, 10^{7}$ e $10^{8}$ UFC.g ${ }^{-1}$, respectivamente. 
Os valores médios resultantes das notas atribuídas pelos provadores foram: 6,7 para o Queijo A $\left(10^{6} \mathrm{UFC}^{-g^{-1}} \mathrm{de}\right.$ L. acidophilus); 6,5 para o B (10 UFC. ${ }^{-1}$ de L. acidophilus); e 6,4 para o C ( $10^{8}$ UFC.g ${ }^{-1}$ de L. acidophilus), demonstrando que os queijos apresentaram boa aceitabilidade independente da população de bactéria probiótica. Em queijo Minas frescal, produzido pelo processo tradicional, Jurkiewicz, 1999, também verificou que a adição de L. acidophilus La 145, não influenciou as características sensoriais do produto durante 15 dias de estocagem a $5{ }^{\circ} \mathrm{C}$.

\section{Conclusões}

O queijo Minas frescal produzido a partir de retentados, obtidos por ultrafiltração de leite, mostrou ser um produto adequado para a incorporação de L. acidophilus, sendo uma nova alternativa de alimento probiótico. Durante 28 dias de armazenamento do queijo a $5{ }^{\circ} \mathrm{C}$, a população da bactéria probiótica permaneceu e não apresentou decréscimo significativo. A variação da concentração de inóculo de $L$. acidophilus $\left(10^{6}\right.$, $10^{7}$ e $10^{8} \mathrm{UFC}^{-1}$ ) no queijo não alterou as características físicoquímicas e sensoriais do produto.

\section{Referências bibliográficas}

BRULE, G.; MAUBOIS, J. L.; FAUQUANT, J. Étude de la teneur en elements minéraux des produits obtenus lors de l'ultrafiltration du lait sur membrane. Le Lait, v. 54, n. 533-540, p. 600-615, 1974.

BURITI, F. C. A. et al. Probiotic potential of minas fresh cheese prepared with the addition of Lactobacillus paracasei. Lebensmittel Wissenschaft und Technologie, v. 38, n. 2, p. 173-180, 2005a.

BURITI, F. C. A.; ROCHA, J. S.; SAAD, S. M. I. Incorporation of Lactobacillus acidophilus in Minas fresh cheese and its implications for textural and sensorial properties during storage. International Dairy Journal, n. 15, p. 1279-1288, 2005 b.

CASIRAGHI, E. M.; PERI, C.; PIAZZA, L. Effect of calcium equilibrium on the rate of syneresis and on the firmness of curds obtained from milk UF retentates. Milchwissenschaft, v. 42, n. 4, p. 232-235, 1987.

CORBO, M. R. et al. Microbiological and biochemical properties of canestrato pugliese hard cheese supplementedwith bifidobacteria. Journal of Dairy Science, n. 84, p. 551-561, 2001.

CUNHA, C. R. et al. Efeito do fator de concentração do retentado no rendimento de queijo minas frescal de baixo teor de gordura fabricado por ultrafiltração. Ciência e Tecnologia de Alimentos, v. 22, n. 1, p. 76-81, 2002a.

CUNHA, C. R. et al. Efeito do fator de concentração do retentado na composição e proteólise de queijo minas frescal de baixo teor de gordura fabricado por ultrafiltração. Ciência e Tecnologia de Alimentos, v. 22, n. 1, p. 82-87, 2002 b.

DAIGLE, A. et al. Production of probiotic cheese (cheddar-like cheese) using enriched cream fermented by bifidobacterium infantis. Journal of Dairy Science, v. 82, n. 6, p. 1081-1091, 1999.

DORNELLAS, J. R. F. Efeito do tipo de coagulante e acidificante no rendimento, proteólise e "shelf life" do queijo Minas frescal. Campinas, 1997. Dissertação (Mestrado) - UNICAMP.
DRUMOND, F. B.; WERKEMA, M. C. C.; AGUIAR, S. Análise de variância: comparação de várias situações. Belo Horizonte: Fundação Christiano Ottoni, 1996. 302 p. (Série Ferramentas da Qualidade). ISBN 8585447311.

DUTCOSKY, S. D. Análise sensorial de alimentos. Curitiba, PR: Champagnat, 1996. 123p.

GARDINER, G. et al. Evaluation of cheddar cheese as food carrier for delivery of a probiotic strain to the gastrointestinal tract. Journal of Dairy Science, v. 82, n. 7, p. 1379-1387, 1999.

GOMES, A. M. P.; MALCATA, F. X. Development of probiotic cheese manfactured from goat milk: response surface analysis via technological manipulation. Journal of Dairy Science, v. 81, n. 6, p. 1492-1507, 1998.

GRIPON, J. C. et al. Etude du rôle des micro-organismes et des enzymes au cours de la maturation des fromages. II Influence de la presure comerciale. Le Lait, v. 55, n. 548, p. 502-516, 1975.

JURKIEWICZ, C. H. Avaliação das características microbiológicas, físico-químicas e sensoriais de queijo minas frescal elaborado com cultura probiótica de Lactobacillus acidophilus. São Paulo, 1999. 134 p. Tese (Doutorado) - Faculdade de Ciências Farmacêuticas, USP.

KINDSTED, P. S.; KOSIKOWSKI, F.V. Improved Complexometric Determination of Calcium in Cheese. Journal of Dairy Science, v. 68, n. 4 , p. 806-809, 1985.

MISTRY, V. V.; KOSIKOWSKI, F. V. Growth of lactic acid bacteria in highly ultrafiltered skim milk retentates. Journal of Dairy Science, v. 68, n. 10, p. 2536-2543, 1985.

O'SUlliVAN, D. J. Primary Sources of Probiotic Cultures. In: Probiotics in food safety and human health. Boca Raton: Taylor \&Francis, 2006.

REID, G. et al. New Scientific paradigms for probiotics and prebiotics. J. Clin. Gastroenterol, v. 37, n. 2, p. 105-118, 2003.

SAARELA, M. et al. Gut bacteria and health foods - the European perspective. International Journal of Food Microbiology, v. 78, n. 1-2, p. 99-117, 2002.

SCHMID, K. et al. Development of probiotic food ingredients. In: Probiotics in food safety and human health. Boca Raton: Taylor \&Francis, 2006.

SANDERS, M. E. Probiotics: Considerations for Human Health. Nutrition Reviews, v. 61, n. 3, p. 91-99, 2003.

SILVA, P. H. F. et al. Físico-Química do Leite e Derivados - Métodos Analíticos. Juiz de Fora, MG: Oficina de Impressão Gráfica e Editora Ltda, 1997. 190 p.

STANTON, C. et al. Probiotic cheese. International Dairy Journal, n. 8, p. 491-496, 1998.

VAN DENDER, A. G. F. Contribuição ao estudo do uso da ultrafiltração de leite na fabricação de queijo Minas Frescal. Campinas, 1995. Tese (Doutorado) - FEA/UNICAMP.

VINDEROLA, C. G. et al. Viability of probiotic (Bifidobacterium, Lactobacillus acidophilus and Lactobacillus casei) and nonprobiotic microflora in argentinian fresco cheese. Journal of Dairy Science, n. 83, p. 1905-1911, 2000.

WILLIAMS, S. (Ed.). Official methods of analysis of the Association of Official Analytical Chemists. 14 ed. Arlington, 1984.

WOLFSCHOON-POMBO, A. F. Índices de proteólise em alguns queijos brasileiros. Boletim do leite, n. 661, p. 23-40, 1979. 